\title{
The Relation between Success and Absenteeism at Esogu English Preparatory School
}

\author{
Ümit Özkanal \\ Eskişehir Osmangazi Üniversitesi, Yabancı Diller Bölümü Çamlık Kampüsü 26010 Eskişehir, Turkey \\ Email: ozkanal@gmail.com \\ Nadire Arıkan \\ Eskişehir Osmangazi Üniversitesi, Yabancı Diller Bölümü Çamlık Kampüsü 26010 Eskişehir, Turkey \\ Email: nadirearikan@gmail.com
}

\begin{abstract}
Attendance to school where students are expected to be exposed to necessary information, abilities and attitudes required by the community they live in has always been considered as a crucial element in attaining success. This study aims to search if there is any correlation between absenteeism and academic success at ESOGU FLD. The participants were the students who enrolled in the ESOGU FLD during 2007-2008 and 2008-2009 academic years. Analyzing their written records of absenteeism and success, the relation between success and absenteeism were investigated. In addition to this, whether gender and students' majors were factors in determining students successes in relation to absenteeism was also investigated. The findings show that attendance to the classes regularly significantly contributes to high achievement level. The study also suggests that while students' major is a significant factor contributing to students' achievements, gender proved to be an insignificant factor.
\end{abstract}

Index Terms — success, absenteeism, gender, students' majors, achievement

\section{INTRODUCTION}

Although recent developments in information and technology have changed many things in education, school system still seems to be the most important element in it. School system is considered to be the first place where individuals learn to live in a community, which is a crucial step for them. Therefore, any school which is formed to educate and train people should plan what kind of information and abilities are going to be delivered so that the students can become the ideal people that a country needs to develop. The aforementioned information, abilities and attitudes aimed for students are delivered via some teaching techniques at school (Erden, 1998). To what extent students have reached these is evaluated via some evaluation techniques and the result may be called as academic success or performance. It is defined as the level of reaching to the pre-determined, desired objectives (Silah, 2003). In order to reach these desired goals, one must carry out some school based activities and be successful based on the necessary evaluation techniques.

\section{ABSENTEEISM AND ACADEMIC SUCCESS}

As mentioned above, school is a kind of social organization in which people start socialization as well as being equipped with knowledge that they will use in their future lives. In order to be academically successful, there are some steps one must follow seriously. One of the most important of them is to attend classes and/or laboratories so that one can get equipped with necessary knowledge and abilities which are crucial academically and for life in the future.

As known, there are many factors that affect academic success, but non-attendance or absenteeism is the study objective of this paper since it is thought that absenteeism is a key concept in academic success, especially in the case of higher education as it is at Eskisehir Osmangazi University English Preparatory School.

Absenteeism may be defined as not coming to school or not following the courses without having a valid excuse (Wisconsin, 2000). In another definition, it is said that it may be called as school refusal behaviour (SRB) based on the definition of Kearney and Silverman (1990), stating a kind of difficulty attending school or remaining in school for the whole day.

Absenteeism may also be viewed as a personal decision related to ability and the motivation to attend (Kottasz, 2005). In the relevant literature, it is stated that absenteeism may be caused by family, school, personal problems, peer and gender related issues (Kadi, 2000). For some students school attendance may be conceived as a kind of punishment acting a negative reinforcement. Similarly, for some, schools and their curricula may be the contributing causes of absenteeism (Williams, 2001). Family health and/or financial concerns, drug and alcohol use, poor school climate, transportation problems and different attitudes towards education may also be mentioned among the causes of absenteeism (Teasley, 2004). Another cause for absenteeism is motivation; there is a crucial difference between a motivated student and an unmotivated one who feels she/he has to go to school (Kottasz, 2005). 
Student absenteeism is also an important concern in higher education since it results in inadequate learning and poor academic success because of the classes missed (Friedman, Rodrigues and McComb, 2001; Marburger, 2001). It is important in higher education as this does not only affect the absent student and his/her academic success, but it can also affect the lecturers, other present students and thus the whole learning environment at school (Salisa and others, 2009). School is a social organization and interaction among students and their instructors is very important because the school lets them socialize professionally by observing the others, especially faculty members and recognizing them as role models (Fjortoft, 2005; Hammer and others, 2003). It is stressed that those who miss the class frequently are the ones who do not realize that the classroom or school is a community that they belong to and must be a part of and that when they do not attend classes, their learning level decreases and it becomes difficult to reach desired academic goals (Cronon, 1998; Brown, 2002).

It is interesting to note that among university students absenteeism days are frequently are Mondays or Fridays, which shows to be quite trivial reasons of absenteeism stating that this kind of absenteeism does not have a concrete reason (Timmins, 2002; Rodgers, 2002). This situation is the same at ESOGU FLD since students mainly prefer not to attend on Monday mornings and Friday afternoons. The information has been obtained via an interview carried out with the office chair responsible for attendance and documents investigated by the researchers.

It may be important to note that while some schools in some countries do not impose clear messages about the importance of attendance and students cannot be aware of its importance, this is not the case at ESOGU FLD. Attendance to classes is very important and students may not attend only $10 \%$ of the total class hours. To illustrate, if a level of English prep class has 800 hours of lessons, a student may not attend only 80 hours of lessons during the academic year, namely both in autumn and spring terms. When students exceed this number, they can take neither the final exam nor the make-up exam (ESOGU Rehber, 2009). Medical reports are not valid for the absenteeism and the right of non-attendance up to $10 \%$ is for some situations like being sick and not coming the school due to this or any other unexpected events one may face. This is announced to all students at the beginning of the academic year in a warm-up meeting and students may reach any information they need from the web-site of the department.

\section{RESEARCH QUESTIONS}

This study aims to search if there is any correlation between absenteeism and academic success at ESOGU FLD. The main research question is:

Is there any correlation between absenteeism and academic success?

Based on this main question, two sub-questions were added as:

Is there any correlation between absenteeism and academic success with respect to gender?

Is there any correlation between absenteeism and academic success with respect to majors?

\section{Methodology}

In order to find out if there is any correlation between absenteeism and academic success, the formal written absenteeism records and overall academic success of students having studied at ESOGU FLD in two academic years, 2007-2008 and 2008-2009 were investigated.

The records of each term were analyzed in detail. For 2007-2008 academic year, 413 students' records were analyzed while for 2008-2009, 731 students' records in total were analyzed. The records were grouped according to the students' groups, namely elementary, pre-intermediate and intermediate levels in English, French and German classes since in each group the right of non-attendance was different.

The records were on Microsoft Excel and the correlations were calculated in this program. The students' grade point averages, the success ratio of final exam and absenteeism and general academic success and absenteeism for each academic year were correlated with the percentages of absenteeism. Then, the results were shown and depicted in the tables.

\section{FINDINGS AND DISCUSSION}

The present study was designed to investigate whether there is any relationship between absenteeism and academic success in a FLD context, namely Eskişehir Osmangazi University FLD. The data gained from student records were analyzed and presented in the tables 1 and 2. The data of two academic years were taken into account to justify the relation between academic success and absenteeism based on aforementioned criteria.

It must be noted that in the calculations of such correlations 0 and 0.25 is defined as the poor level and $0.50-0.60$ as medium, $0.70-0.85$ as strong and $0.90-1$ as very strong. 
TABLE 1.

THE CORRELATION BETWEEN ABSENTEEISM AND SUCCESS FOR 2007-2008.

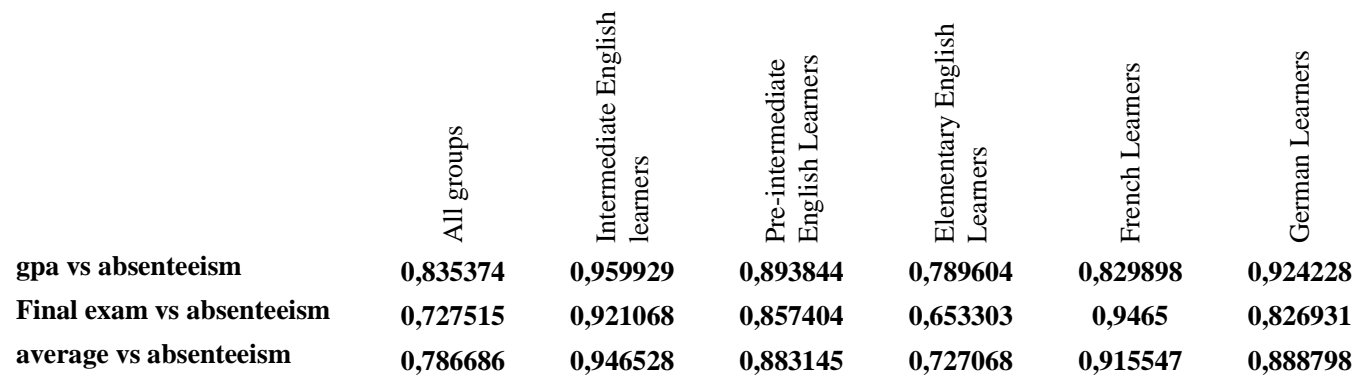

As seen in the table 1, the correlation was calculated based on three different criteria: the correlation between grade point average and absenteeism, the success ratio of final exam and absenteeism, and general academic success and absenteeism. The reason why all these three criteria were included was to see if there were any significant differences among the criteria.

When the correlations are examined, it can be seen that grade point average in all levels is above 0.70 , which means there is a significant correlation between them. It could therefore be suggested that students who attend the classes regularly have a higher achievement level.

When the correlation between final exam and absenteeism is studied, it is clear that in all levels except for elementary the correlation proved to be significant. Although the correlation in the elementary level is just below 0.70 , it may be expressed that having 0.65 may be seen a significant value.

When the correlation of the general academic success and absenteeism is studied, it can be seen that the correlation in each level is above 0.70 , which means there is a close and significant correlation between them. Therefore, it may be stated that attending all the classes contributed to general achievement in all levels and the students finished the prep school successfully.

TABLE 2.

THE CORRELATION BETWEEN ABSENTEEISM AND SUCCESS FOR 2008-2009.

\begin{tabular}{|c|c|c|c|c|c|c|}
\hline & 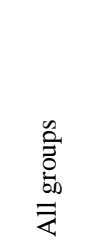 & 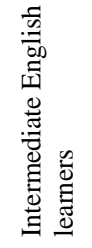 & 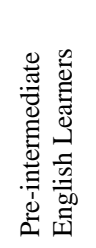 & 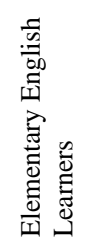 & 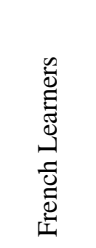 & 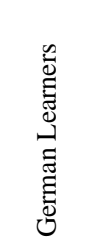 \\
\hline gpa vs absenteeism & $\mathbf{0 , 8 4 0 7}$ & 0,9453 & 0,7005 & 0,8254 & 0,8586 & 0,9332 \\
\hline Final exam vs absenteeism & 0,6814 & $\mathbf{0 , 8 9 2}$ & 0,6018 & 0,6424 & 0,7671 & $\mathbf{0 , 8 1 8 8}$ \\
\hline average vs absenteeism & 0,7646 & $\mathbf{0 , 9 3 0 3}$ & 0,6674 & 0,7379 & $\mathbf{0 , 8 1 7 2}$ & 0,896 \\
\hline
\end{tabular}

As seen in Table 2, the correlation was calculated based on three different criteria: the correlation between grade point average and absenteeism, the success ratio of final exam and absenteeism, and general academic success and absenteeism. The reason for including all these three criteria was to see if there were any significant differences among the criteria.

When the correlations are examined, it can be seen that grade point average in all levels is above 0.70 , which means there is a significant correlation between. Therefore, it can be stated that students who attend the classes regularly have high achievement level.

When the correlation between final exam and absenteeism is studied, it is seen that although the correlation between them is not so significant, it is observed that they are still high.

When the correlation of the general academic success and absenteeism is studied, it can be seen that in all levels except pre-intermediate level (0.66), the correlation is above 0.70 , which means there is a close and significant correlation between them. The difference between the other levels and that of pre -intermediate is only 0.4 , which does not show a considerable difference. Therefore, it may be stated that attending all the classes contributed to general achievement in all levels and the students finished the prep school successively.

Although both tables show the correlations of two different academic years with different students, it can be easily stated that attendance is a very significant contributor of academic success as seen in the tables clearly. 
TABLE 3 .

THE CORRELATION BETWEEN ABSENTEEISM AND SUCCESS WITH RESPECT TO GENDER

$\begin{array}{lllll}\text { 2007-2008 } & \text { male } & 0,84983606 & 0,740869 & 0,799351 \\ \text { Academic Year } & \text { female } & 0,797565 & 0,70885 & 0,757906 \\ 2008-2009 & \text { male } & 0,840087102 & 0,6796 & 0,8401 \\ \text { Academic Year } & \text { female } & 0,721120961 & 0,545233 & 0,634449\end{array}$

As seen in the table 3, the correlation was calculated based on gender differences. When the correlations are investigated, it can be seen that in 2007-2008 academic year the correlation for both males and females is above 0.70, which means there is a significant correlation and this also shows that gender is not an important factor to affect success.

When the correlation between final exam and absenteeism between genders is studied, it is seen that both males and females have lower correlation, which again shows that gender does not play an important role in the relation between success and absenteeism.

TABLE 4.

THE CORRELATION BETWEEN ABSENTEEISM AND SUCCESS WITH RESPECT TO MAJORS

$\begin{array}{llll}\mathbf{2 0 0 7 - 2 0 0 8} \text { Academic Year } & & \\ \text { Departments } & \text { gpa vs absenteeism } & \text { final grade vs absenteeism } & \text { Average grade vs absenteeism } \\ \mathbf{1 3 1 4} & 0,908065 & 0,830434 & 0,876954 \\ \mathbf{1 5 1 2} & 0,8926 & 0,821462 & 0,862308 \\ \mathbf{1 5 1 7} & 0,655826 & 0,485206 & 0,571285 \\ \mathbf{1 5 1 8} & 0,840521 & 0,670537 & 0,761201 \\ \mathbf{1 5 2 1} & 0,890108 & 0,791318 & 0,85556 \\ \mathbf{2 6 1 1} & 0,538827 & 0,499626 & 0,522253 \\ \mathbf{2 0 0 7 - 2 0 0 8} \text { Academic Year } & & \\ \mathbf{D e p a r t m e n t s} & \text { gpa vs absenteeism } & \mathbf{f i n a l} \text { grade vs absenteeism } & \text { Average grade vs absenteeism } \\ \mathbf{1 3 1 4} & 0,915 & 0,813 & 0,8763 \\ \mathbf{1 5 1 2} & 0,811732 & 0,653664 & 0,733953 \\ \mathbf{1 5 1 7} & 0,782894 & 0,553792 & 0,663954 \\ \mathbf{1 5 1 8} & 0,8179 & 0,674 & 0,7531 \\ \mathbf{1 5 2 1} & 0,875703 & 0,786597 & 0,842134 \\ \mathbf{2 6 1 1} & 0,860044 & 0,671539 & 0,78055\end{array}$

As seen in the table 4, the correlation was calculated based on majors of students. The reason for including this is to see if there are any significant differences among the majors.

When the correlations are investigated, it can be seen that except two majors the correlation between success and absenteeism proved to be significant, having strong correlation rates. The problem with these two majors may be that the students are aware that they will just follow few of the courses in English in their departments.

\section{CONCLUSION}

The findings of the current study show that attendance to the classes regularly significantly contributes to high achievement level. Therefore, it can be said that the study is congruent with the findings of previous studies in that when students attend classes regularly, they become successful whereas student absenteeism yields inadequate learning and academic failure (Friedman, Rodrigues and McComb, 2001; Marburger, 2001). In addition, another finding in the present study suggests that the level of success changes according to students' majors; therefore, it is a significant factor contributing to students' achievements. Gender, however, was determined to be an insignificant factor to affect success.

Considering these findings, it is important to make students attend the classes regularly, so schools should take necessary precautions to provide this. It is also important to ensure that students realize they will need English not only at the university but also in their job lives to motivate and help them take English learning seriously.

In this study, there are some limitations. The formal written records were used; however, they were not supported by means of interviews. In the future studies, interviews with the students may be helpful to shed light on the issue. Furthermore, a study on the causes of absenteeism may also be investigated and necessary precautions to prevent this may be taken in order to increase achievement level in the school.

\section{REFERENCES}

[1] Brown, W. (2002). Why I do not Let Students Cut My Classes. In: Gordon VN, Minick TL, eds. Foundations: A Reader for New College Students. Belmont, CA: Wadsworth;100-2. 
[2] Cronon, W. (1998). Only Connect......: The Goal of a Liberal Education. Am. Scholar. 67(4):73-80.

[3] Erden, M . (1998). Introduction to Teaching Profession. İstanbul: Alkim Publications.

[4] Esogü Rehber. (2009). Eskisehir: ESOGU Publications.

[5] Fjortoft, N. (2005). Students' Motivations for Class Attendance. American Journal of Pharmaceutical Education. 69 (1).

[6] Friedman, P., Rodrigues, F. and McComb, J. (2001). Why Students Do and Do Not attend Class. College Teaching, 49, 124-133.

[7] Hammer, D.P., Berger B.A., Beardsley, R.S. and Easton, M.R. (2003). Student Professionalism. American Journal of Pharmaceutical Education. 67 (3).

[8] Kadi, Z. (2000). The Reasons of Absenteeism of Primary School Students in Adana. Unpublished MA Thesis. Malatya: İnönü University Social Sciences Institute.

[9] Kearney, C. A. and Silverman, W. K. (1990). A preliminary Analysis of a Functional Model of Assessment and Treatment for School Refusal Behavior. Behavior Modification.1, 340-366.

[10] Kottasz, R. (2005). Reasons for Student Non-Attendance at Lectures and Tutorials: An Analysis. Investigations in University Teaching and Learning. 2(2)

[11] Marburger, D. R. (2001). Absenteeism and Undergraduate Exam Performance. Journal of Economic Education, 32, 99-109.

[12] Rodgers, J.R. (2002). Encouraging Tutorial Attendance at University Did Not Improve Performance. Australian Economic Papers, September, 255-266

[13] Salisa, C.W. and others. (2009). Factors Influencing Pharmacy Students' Attendance Decisions in Large Lectures. American Journal of Pharmaceutical Education 7, (5)

[14] Silah, M. (2003). The Place and Importance of Absenteeism Which is An Important factor Affecting the Academic Success Among University Students. Educational Studies Journal. 10:102-115.

[15] Teasley, M. (2004). Absenteeism and truancy: risk, protection, and best practice implications for school social workers. Children \& Schools, 26(2), 117-128.

[16] Timmins, F. (2002). Absenteeism among Nursing Students- Fact or Fiction? Journal of Nursing Management 10 (5): $251-264$.

[17] Williams, L. L. (2001). Student Absenteeism and Truancy: Technologies and Interventions to Reduce and Prevent Chronic Problems Among School-Age Children. Available at:http://teach.valdosta.edu/are/Litreviews/vol1no1/williams_litr.pdf

[18] Wisconsin Legislative Audit Bureau. (2000). Truancy Reduction Efforts: A Best Practice Review. Spectrum: Journal of State Government 73 (4), 13-15

Ümit Özkanal has been an English instructor at Eskisehir Osmangazi University Foreign Languages Department for 15 years. He has got a PhD degree from Anadolu University Educational Sciences Institute, Curriculum and Teaching Program. His interests are curriculum evaluation, development and EFL.

Nadire Arıkan has been an English instructor at Eskisehir Osmangazi University Foreign Languages Department since 1999. She has got a MA degree from Bilkent University, Social Sciences Institute, MA TEFL Program. Her interests are teacher training, testing, EFL, and ESP. 